\title{
A public health approach to ensure equitable, person-centred solutions to address ear disease, hearing loss and deafness
}

\section{Catherine M McMahona,d, Caitlin M Barr ${ }^{\mathrm{b}}$, Jessica Vitkovic ${ }^{\mathrm{b}}$ and Bamini Gopinathc}

a HEAR Centre, Macquarie University, Sydney, NSW, Australia

b Soundfair, Melbourne, VIC, Australia

${ }^{c}$ Macquarie University Hearing, Macquarie University, Sydney, NSW, Australia

dCorresponding author: cath.mcmahon@mq.edu.au

\section{Article history}

Publication date: 2 December 2021

Citation: McMahon CM, Barr CM, Vitkovic J, Gopinath B. A public health approach to ensure equitable, person-centred solutions to address ear disease, hearing loss and deafness. Public Health Res Pract. 2021;31(5):e3152133. https://doi. org/10.17061/phrp3152133
Language and communication are foundational for mental and physical health, social and cultural identity, and prosperous societies. For most people, good hearing health is critical for developing and maintaining language, listening and learning, and developing and consolidating social connections - vital to normal childhood development and successful ageing. For those born Deaf, sign language and accessible communication are core to an inclusive society. However, living with hearing loss or being Deaf is complex and doused in inequity, and complicated by a society and environment that disables and stigmatises hearing loss. Ear and hearing care is poorly integrated into systems of health globally and centres on the provision of hearing devices to individuals with hearing loss. As a result, hearing loss is framed through a disability lens, leading to fragmentation of services and deeply entrenched stigmatisation with low levels of trust in the system and provider.

Public health solutions, however, can benefit populations. Further, balancing lenses of health and disability with a social lens enables individuals and promotes inclusive societies. Approaches in hearing health lag behind other health initiatives which have seen considerable gains as a result of reframing clinical challenges as public health ones, and promoting collective action, innovation and transformation. Today, there is wider recognition and appreciation of the challenges that hearing loss and deafness brings at an individual and societal level. A burning platform exists, fuelled by accumulating evidence of the significant impacts of hearing loss across the life course - highlighting the need to act. Yet, coupled with the paucity of data and disparate voices of stakeholders, policy makers cannot know what to prioritise and where to allocate increasingly scarce resources. Central to this are two key opportunities. The very first World Report on Hearing (launched 3 March 2021) ${ }^{1}$ calls for all governments to integrate person-centred ear and hearing care into national health plans. This seminal document 
comprehensively summarises current evidence and frames ear disease and hearing loss as a major public health problem. Importantly, it provides a global platform to unite stakeholders to advocate for change. Two years prior, Australia's stakeholder-led Roadmap for Hearing Health ${ }^{2}$ was endorsed by the now-defunct Council of Australian Governments, highlighting local challenges and providing 147 recommendations to address these challenges. Yet, cross-sectoral agreement and funding for a 'national action plan' - needed to coalesce action and benefit all - are lacking.

In this issue of Public Health Research \& Practice, eight papers, in different ways, highlight key action areas for Australia from the perspectives of research, key opinion and lived experience, and examples of policy and practice, with the purpose of reinforcing contemporary challenges that must be overcome. Harkus and colleagues' qualitative study of urban Aboriginal parents and carers highlight the lack of a systematic approach to ear checks for this at-risk population. ${ }^{3}$ Consequently, a high burden is placed on families to recognise signs and symptoms of ear disease and hearing loss in children, to determine how to navigate the complex system of health, and to advocate for timely treatment. Kong. Calma and Rambaldini highlight system inequities and lack of cultural safety, referring to this as "the wrong system built for the wrong community". ${ }^{4}$ Access challenges, however, are pervasive. Beaver and Carty identify that Deaf people experience health literacy as one of the most common barriers in the healthcare system. ${ }^{5}$ Despite the well-recognised high prevalence of hearing loss for older adults, in a four-country study, McMahon and colleagues show that system and structural barriers continue to create low levels of trust in hearing services, challenged further by high levels of stigma which has been known for decades. ${ }^{6}$ Proactive approaches are needed. Kiely and Anstey advocate for hearing health to be part of a broader public health strategy, recommending evidencebased prevention is critical to the approach. ${ }^{7}$ The need for targeted screening programs for children from socioeconomically disadvantaged settings is considered by McMahon, McLennan and colleagues. ${ }^{8}$ Bennett and colleagues demonstrate how strengthening opportunities for general practitioners to manage hearing loss in partnership with those who have hearing loss could more effectively embed hearing care into primary health care practice. ${ }^{9}$ Further opportunities for change should consider emerging industry and market trends - Willink and colleagues consider how policy changes in the US which increase access to hearing devices through new markets might have an impact globally. ${ }^{10}$

\section{Time for a little less conversation, a little more action}

Ear disease, hearing loss and deafness have been the topic of numerous reports filled with recommendations for policy, practice and research. Despite commonalities, few have translated into policy change; ear and hearing care practice is slow to accept change; and research lacks sustained and secure funding needed to innovate and robustly evaluate new models of care. With a projected one in four Australians set to experience hearing loss by $2050^{11}$, those affected find themselves trying to stay afloat amid fast-paced technological changes, with complex and imposing funding arrangements, while experiencing the well-evidenced psychosocial, emotional and educational impacts. Adults wait close to 10 years before taking action on changes in hearing and when they do, they are fast tracked into a one-size-fits-all model of hearing service delivery. Children born with hearing loss and deafness are offered technology shrouded in support, with little culturally considered conversation about their identity and Deaf culture, or how families might need to navigate this.

Here, we call for hearing equity. Going beyond the prevailing medical model of hearing health, we need to look holistically at the broader determinants of health to recognise that the true needs of people with hearing loss and deafness exceed amplification of sound. Decision makers must be held to account and set clinical, research and policy priorities to ensure hearing loss and deafness are strategically positioned as a public health priority. Hearing loss and deafness should no longer be stigmatised; but viewed as a widely acknowledged experience that requires society-wide action.

\section{A national action plan provides a framework to drive collaborative efforts}

To achieve this, four key pillars are envisioned:

1. Improve the capture and use of contemporary robust data to better understand health and psychosocial impacts as well as risk factors of hearing loss. This will determine where resources should be prioritised to strengthen treatment, support and outcomes.

2. Target improvements to the hearing healthcare system to improve access (such as for cultural and linguistically diverse populations), improve affordability, and address biopsychosocial impacts across the life course and life stage. Participatory approaches, such as co-design, are critical to system design improvements. System changes must precede awareness campaigns, or such campaigns will fail.

3. Develop new and strengthen current education campaigns by partnering with people with lived experience in the general community and among health professionals. These should promote self- and societal-prevention and management of ear disease and hearing loss, and escalate society-wide actions to remove accessibility and inclusion barriers.

4. Increase linkages between hearing health and other sectors, for example, primary health and social sectors to improve integrated care, and design and engineering to increase the accessibility of built environments. 
Such change can only be accomplished by collective action, authentic listening and engagement with those with hearing loss or deafness, and government and sector support.

\section{Acknowledgements}

This special issue of Public Health Research \& Practice was supported by and developed in partnership with Soundfair, Macquarie University Hearing and Macquarie University's HEAR Centre.

\section{Peer review and provenance}

Internally peer reviewed, invited.

\section{Competing interests}

None declared.

\section{Author contributions}

$\mathrm{CM}, \mathrm{CB}$ and $\mathrm{BG}$ were responsible for the design, drafting and editing of the manuscript. JV was responsible for the design, reviewing and editing of the manuscript.

\section{References}

1. World Health Organisation. World report on hearing. Geneva: WHO; 2021 [cited 2021 Nov 26]. Available from: www.who.int/publications/i/item/world-report-on-hearing

2. Australian Government Department of Health. Roadmap for hearing health - Hearing Health Sector Committee. Canberra: Department of Health; 2019 [cited 2021 Nov 26]. Available from: www1.health.gov.au/internet/ main/publishing.nsf/Content/CDFD1B86FA5F437CCA25 83B7000465DB/\$File/Roadmap\%20for\%20Hearing\%20 Health.pdf

3. Harkus SF, Caso KAJ, Hall ST, Kung C, Manton TN, Murthy SJ, et al. 'Sometimes they're gammin, playing tricks, but sometimes it's ears.' Perspectives of parents and carers of young urban Aboriginal and Torres Strait Islander children on their journey to diagnosis of persistent ear health and hearing problems. Public Health Res Pract. 2021;31(5):e3152129.
4. Calma T, Kong KM, Rambaldini B. How can we create equitable access to hearing healthcare in Australia? Interview with Prof. Tom Calma, Prof. Kelvin Kong and Hon. A/Prof. Boe Rambaldini. Public Health Res Pract. 2021;31(5):e3152126.

5. Beaver S, Carty B. Viewing the healthcare system through a deaf lens. Public Health Res Pract. 2021;31(5):e3152127.

6. McMahon CM, Mosley CL, Pichora-Fuller MK, Davis AC, Baylor CR, Yorkston KM, Tremblay KL. Older adults' perceptions of current and future hearing healthcare services in Australia, England, US and Canada. Public Health Res Pract. 2021;31(5):e3152128.

7. Kiely KM, Anstey KJ. Putting age-related hearing loss on the public health agenda in Australia. Public Health Res Pract. 2021;31(5):e3152125.

8. McMahon CM, McLennan J, Orr NJ, Nash K, Nakad P. Risk factors for Australian school-age children in socioeconomically disadvantaged populations not passing ear and hearing screening. Public Health Res Pract. 2021;31(5):e3152130.

9. Promoting hearing loss support in general practice: a qualitative concept-mapping study. Public Health Res Pract. 2021;31(5):e3152131.

10. Willink A, Reed NS, Boisvert I, McMahon CM, Lin FR. Changes in US hearing aid regulations: possible benefits and risks to Australia. Public Health Res Pract. 2021;31(5):e3152132.

11. Access Economics. Listen hear! The economic impact and cost of hearing loss in Australia. Australia: CRC for Cochrane Implant and Hearing Aid Innovation, Vicdeaf; 2006 [cited 2021 Nov 26]. Available from: hearnet.org.au/ wp-content/uploads/2015/10/ListenHearFinal.pdf

\section{Copyright: (c) (i) (2) (2)}

(c) 2021 McMahon et al. This article is licensed under the Creative Commons Attribution-NonCommercial-ShareAlike 4.0 International Licence, which allows others to redistribute, adapt and share this work non-commercially provided they attribute the work and any adapted version of it is distributed under the same Creative Commons licence terms. See: www.creativecommons.org/licenses/by-nc-sa/4.0/ 